\title{
MCDAN - A Monte Carlo \\ Computer Code for Calculating the Dancoff Correction Factor for Spheres and Rods
}

J. P. McNeece

T. J. Trapp

J. K. Thompson

August 1979

Prepared for the U.S. Department of Energy under Contract EY-76-C-06-1830

Pacific Northwest Laboratory Operated for the U.S. Department of Energy by Battelle Memorial Institute 


\title{
NOTICE
}

This report was prepared as an account of work sponsored by the United States Government. Neither the United States nor the Department of Energy, nor any of their employees, nor any of their contractors, subcontractors, or their employees, makes any warranty, express or implied, or assumes any legal liability or responsibility for the accuracy, completeness or usefulness of any information, apparatus, product or process disclosed, or represents that its use would not infringe privately owned rights.

The views, opinions and conclusions contained in this report are those of the contractor and do not necessarily represent those of the United States Government or the United States Department of Energy.

\author{
PACIFIC NORTHWEST LABORATORY \\ operated by \\ BATTELLE \\ for the \\ UNITED STATES DEPARTMENT OF ENERGY \\ Under Contract EY-76-C-06-1830
}
Printed in the United States of America Available from
National Technical Information Service
United States Department of Commerce
5285 Port Royal Road
Springfield, Virginia 22151

Price: Printed Copy s.

$\therefore$ Microfiche $\$ 3.00$

$\begin{array}{cc} & \text { NTIS } \\ \text { - Pages } & \text { Selling Price }\end{array}$

$001-025 \quad \$ 4.00$

026-050 $\$ 4.50$

051-075 $\$ 5.25$

$076-100 \quad \$ 6.00$

101-125 $\quad 56.50$

$126-150 \quad 57.25$

$151-175 \quad \$ 8.00$

$176.200 \quad \$ 9.00$

$201-225 \quad 59.25$

226-250 $\quad 59.50$

251-275 $\quad \$ 10.75$

$276-300 \quad \$ 11.00$ 
MCDAN - A MONTE CARLO COMPUTER CODE FOR CALCULATING THE DANCOFF CORRECTION FACTOR FOR SPHERES AND RODS

\author{
J.P. McNeece \\ T.J. Trapp \\ J.K. Thompson
}

August 1979

Prepared for the U.S. Department of Energy under Contract EY-76-C-06-1830

Pacific Northwest Laboratory

Richland, Washington 99352 


\section{SUMMARY}

MCDAN is a computer code that uses Monte Carlo techniques to calculate the Dancoff correction factor for arrays of spheres or rods. Neutrons are started from the surface of the sphere (rod) and tracked until they intersect another sphere (rod). The histories of a number of neutrons are statistically combined to give a value for the Dancoff correction factor.

MCDAN was written as a tool to verify the accuracy of an expression for the Dancoff correction factor used in a study of the reactivity effect of fuel particles in uranium-water mixtures. The accuracy of MCDAN has been verified by comparison with tabulated data for systems of two spheres (rods). 
TABLE OF CONTENTS

SUMMARY ............................

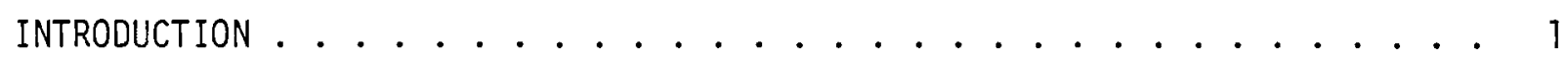

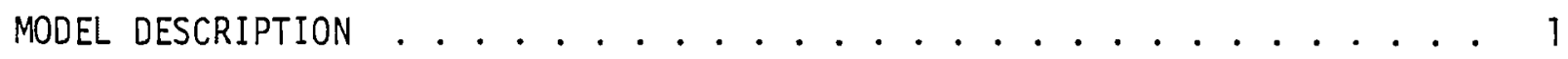

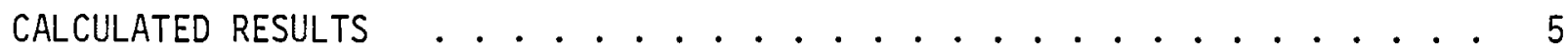

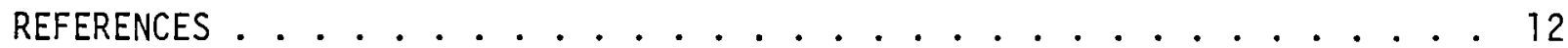

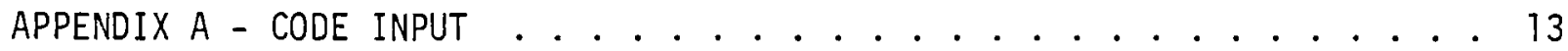

APPENDIX B - CODE LISTING . . . . . . . . . . . . . 14 


\section{LIST OF FIGURES}

I. Model Used in MCDAN ................. 6

II. Coordinate system used in MCDAN ... . . . . . . . . . 7

III. Neutron Interaction with Sphere .......... 7

\section{LIST OF TABLES}

I. Comparison Between MCDAN and Knight's Data ......... 8

II. MCDAN Calculated Dancoff Correction Factors for Spheres, $\Sigma_{\mathrm{m}}=1.0 \mathrm{~cm}^{-1} \ldots \ldots \ldots \ldots \ldots$

III. MCDAN Calculated Dancoff Correction Factors for Spheres, $\Sigma_{\mathrm{m}}=2.0 \mathrm{~cm}^{-1} \ldots \ldots \ldots \ldots$

IV. MCDAN Calculated Dancoff Correction Factors for Spheres, $\Sigma_{\mathrm{m}}=3.0 \mathrm{~cm}^{-1} \ldots \ldots \ldots \ldots \ldots$ 


\section{MCDAN - A MONTE CARLO CODE FOR CALCULATING THE DANCOFF CORRECTION FACTOR FOR SPHERES AND RODS}

\section{INTRODUCTION}

MCDAN is a computer code that calculates the Dancoff correction factor for cubic arrays of spheres or square arrays of rods. The Dancoff correction factor is the probability that neutrons emerging from the surface of a fuel lump with a cosine shaped angular distribution enter another fuel lump without first undergoing a moderator collision.

Neutrons are started from the surface of a sphere (rod) and tracked until they intersect another sphere (rod) or until they exceed a fixed total track length. The histories of a number of neutrons are statistically combined to give a value for the Dancoff correction factor.

Since the rod array calculation is a simplification of the more general sphere array, the following detailed description of the code will be in terms of the sphere case.

\section{MODEL DESCRIPTION}

The model consists of a cubic array of spheres in a "sea" of moderator. The entire matrix can be represented as an array of moderator cubes having a sphere located at the center of each cube. Since each cube is identical, the calculations are performed using only a single cubic cell. Whenever a neutron crosses the cell boundary, its position is reflected such that it re-enters the cube. The two-dimensional model shown in Figure I will help clarify this discussion.

In Figure I-A a neutron leaves the surface of the sphere in cube 1 , misses the sphere in cube 2 and strikes the sphere in cube 3 . In Figure I-B the neutron leaves the sphere and exits the cube at $X 1, Y 1$. The neutron is repositioned to 


$$
\begin{aligned}
& X_{2}=X_{1} \\
& Y_{2}=Y_{1}-\text { lattice pitch }
\end{aligned}
$$

Similarly, after the next exit, the neutron is repositioned to

$$
\begin{aligned}
& X 4=X 3+1 \text { lattice pitch } \\
& Y 4=Y_{3}
\end{aligned}
$$

The path lengths traveled by the neutrons in Figures I-A and I-B are identical. Figure I-B represents a much simpler and more efficient method for tracking the neutrons.

Neutron tracking in the model consists of three basic segments: starting the neutron, determining where the neutron exits from the cube, and determining if the neutron intersects a sphere. After a neutron has hit a sphere or traveled more than a fixed number of mean free paths, typically 10 , in the moderator its total distance traveled, TOTX, is used to evaluate the fractional contribution to the Dancoff correction factor as

$$
c=e^{-T O T X * \Sigma}
$$

where $\Sigma$ is the moderator macroscopic total cross section. A large number of values of $C$ are averaged to obtain the Dancoff correction factor.

Starting a neutron consists of two parts, choosing the starting point on the surface of the sphere and choosing the direction of the neutron. A random number generator capable of producing random numbers uniformly distributed over the interval $(0,1)$ is used in these calculations.

The following algorithm is used to choose the starting point on the sphere's surface. Figure II shows the coordinate system.

a. Pick an angle, $\theta$, uniformly over the range 0 to $2 \pi$

b. Pick an angle, $\phi$, whose cosine is between 1 and -1 (Choosing $\phi$ over 0 to $2 \pi$ biases the location of the starting point.) For the rod case $\phi=\pi / 2$. 
c. Using the sphere radius, $R$, calculate the $x, y$ and $z$ coordinates of the starting point

$$
\begin{aligned}
& x=R \sin \phi \cos \theta \\
& y=R \sin \phi \sin \theta \\
& z=R \cos \phi
\end{aligned}
$$

When choosing the direction of the neutron path, care must be taken to assure that the distribution function of the neutron directions at the sphere's surface is cosine shaped about the radius vector through the starting point. This requirement is met if a random point is chosen inside the sphere and the neutron path given the direction cosines of the line from this interior point to the point on the sphere's surface. The following algorithm is used to pick the random point inside the sphere and determine neutron's direction cosines.

a. Pick a radius, $R_{1}$, over 0 to $R$

b. Pick an angle, $\theta_{1}$, over 0 to $2 \pi$

c. Pick an angle, $\phi_{1}$, whose cosine is between 1 and -1 (for the rod case $\phi_{1}=\pi / 2$ )

d. Calculate the coordinates of the interior point

$$
\begin{aligned}
& x_{1}=R_{1} \sin \phi_{1} \cos \theta_{1} \\
& y_{1}=R_{1} \sin \phi_{1} \sin \theta_{1} \\
& z_{1}=R_{1} \cos \phi_{1}
\end{aligned}
$$

e. Calculate the direction cosines of the neutron path as

$$
\begin{aligned}
& \alpha=\frac{x-x_{1}}{\sqrt{\left(x-x_{1}\right)^{2}+\left(y-y_{1}\right)^{2}+\left(z-z_{1}\right)^{2}}} \\
& \beta=\frac{y-y_{1}}{\sqrt{\left(x-x_{1}\right)^{2}+\left(y-y_{1}\right)^{2}+\left(z-z_{1}\right)^{2}}}
\end{aligned}
$$




$$
\gamma=\frac{z-z_{1}}{\sqrt{\left(x-x_{1}\right)^{2}+\left(y-y_{1}\right)^{2}+\left(z-z_{1}\right)^{2}}}
$$

The distance from the current position of the neutron $(x, y, z)$ to the six surfaces of the cube are calculated and the closest distance, DMIN, is used to determine the exit point. Using DMIN and the direction cosines $\alpha, \beta$ and $\gamma$ the exit point $\left(x_{E}, y_{E}, z_{E}\right)$ is

$$
\begin{aligned}
& x_{E}=x+\alpha * \text { DMIN } \\
& y_{E}=y+\beta * \text { DIMIN } \\
& z_{E}=z+\gamma * D I M N
\end{aligned}
$$

The distance DMIN is summed to generate the total track length, TOTX.

Once the exit point has been established, the neutron is repositioned so that it reenters the cube in the manner discussed earlier.

The neutron will intersect the sphere in the cube if the length of a line from the center of the sphere perpendicular to the neutron path is less than the sphere radius as shown in Figure III. The neutron is at $A$ traveling along $A C$ with direction cosines $\alpha, \beta$ and $\gamma$. The sphere is centered at $B$ with radius $B D . \quad \overline{B C}$ is perpendicular to the neutron path. $\psi$ is the angle between the neutron path and a line from the current neutron position to the center of the sphere. If $B C$ is less than $B D$, then the neutron intersects the sphere at D.

The length of line $\overline{B C}$ is

$$
B C=A B \sin \psi
$$

The angle between the lines $\overline{A B}$ and $\overline{A C}, \psi$, is calculated by first calculating the direction cosines of $\overline{A B}$. They are

$$
\alpha_{1}=\frac{-x}{\sqrt{x^{2}+y^{2}+z^{2}}}
$$




$$
\begin{aligned}
& \beta_{I}=\frac{-y}{\sqrt{x^{2}+y^{2}+z^{2}}} \\
& \gamma_{1}=\frac{-z}{\sqrt{x^{2}+y^{2}+z^{2}}}
\end{aligned}
$$

Then

$$
\cos \psi=\alpha^{\star} \alpha_{1}+\beta^{\star} \beta_{1}+\gamma^{*} \gamma_{1}
$$

If the neutron intersects the sphere at $D$, the track length $A D$ is

$$
A D=\frac{B D * \operatorname{SIN}\left[2 \pi-\psi-\cos ^{-1}(B C / B D)\right]}{\sin \psi}
$$

The value of $A D$ is added to the neutron's track length to give the total track length, TOTX.

Once a neutron has intersected a sphere or exceeded the maximum allowable track length, the Dancoff correction is calculated and a new neutron is started.

\section{CALCULATED RESULTS}

The accuracy of the methods used in this code was tested by comparing the results with data given by knight ${ }^{1}$ for two spheres. It was necessary to modify the code to consider only two spheres but the methods described for starting and tracking the neutrons were not changed. A comparison between the two methods is shown in Table I. The results of the two methods compare very closely.

Tables II - IV give MCDAN calculated Dancoff correction factors for systems having various sphere radii, sphere voume fractions and moderator cross sections. 

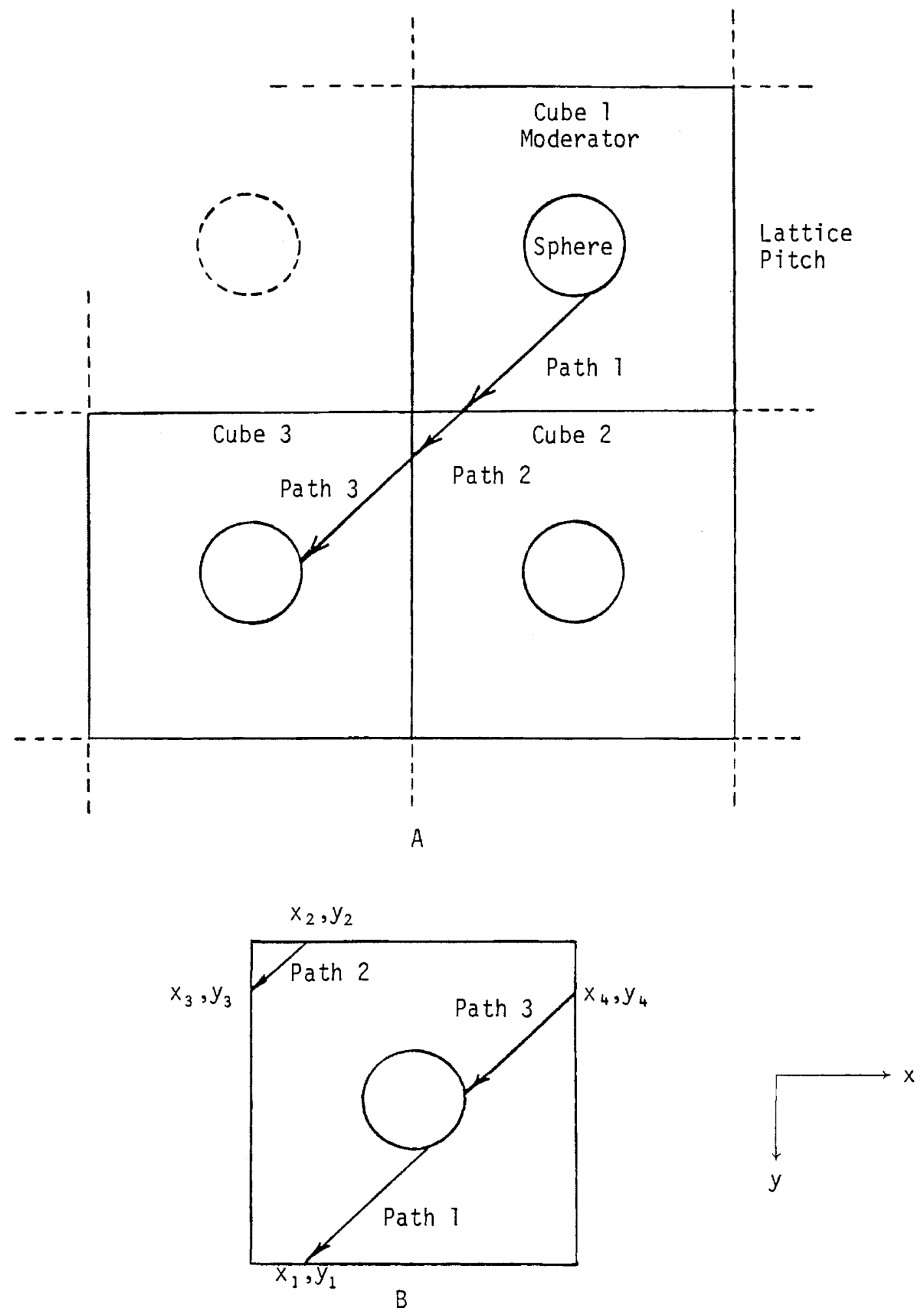

FIGURE I. Model Used in MCDAN 


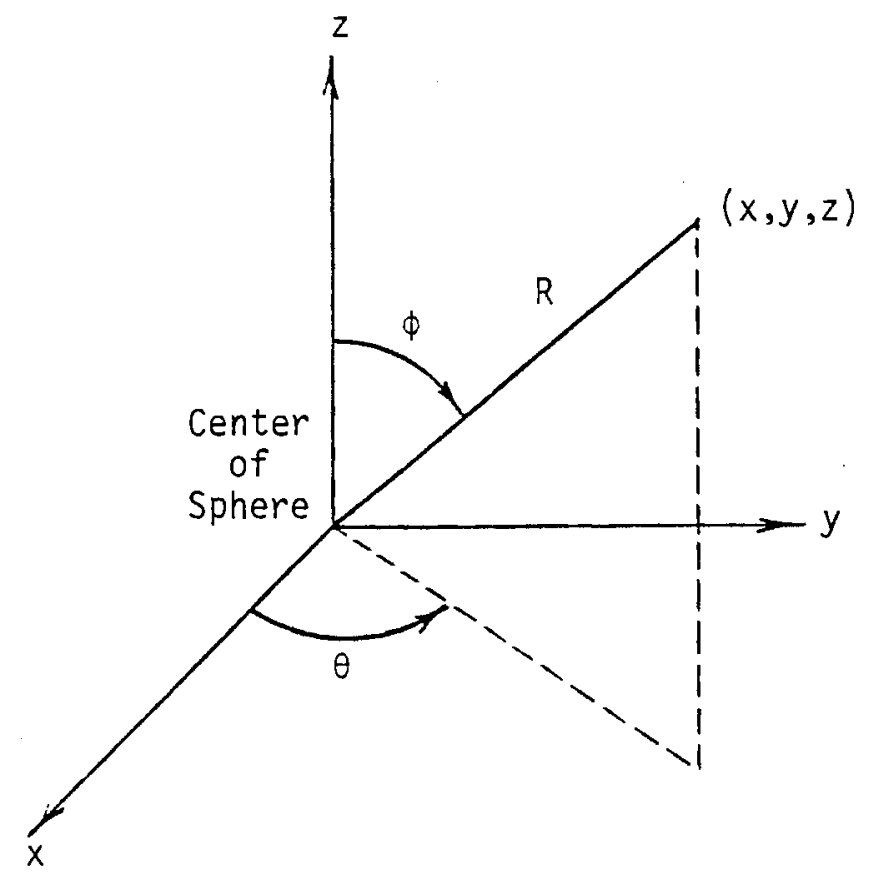

FIGURE II. Coordinate System Used in MCDAN

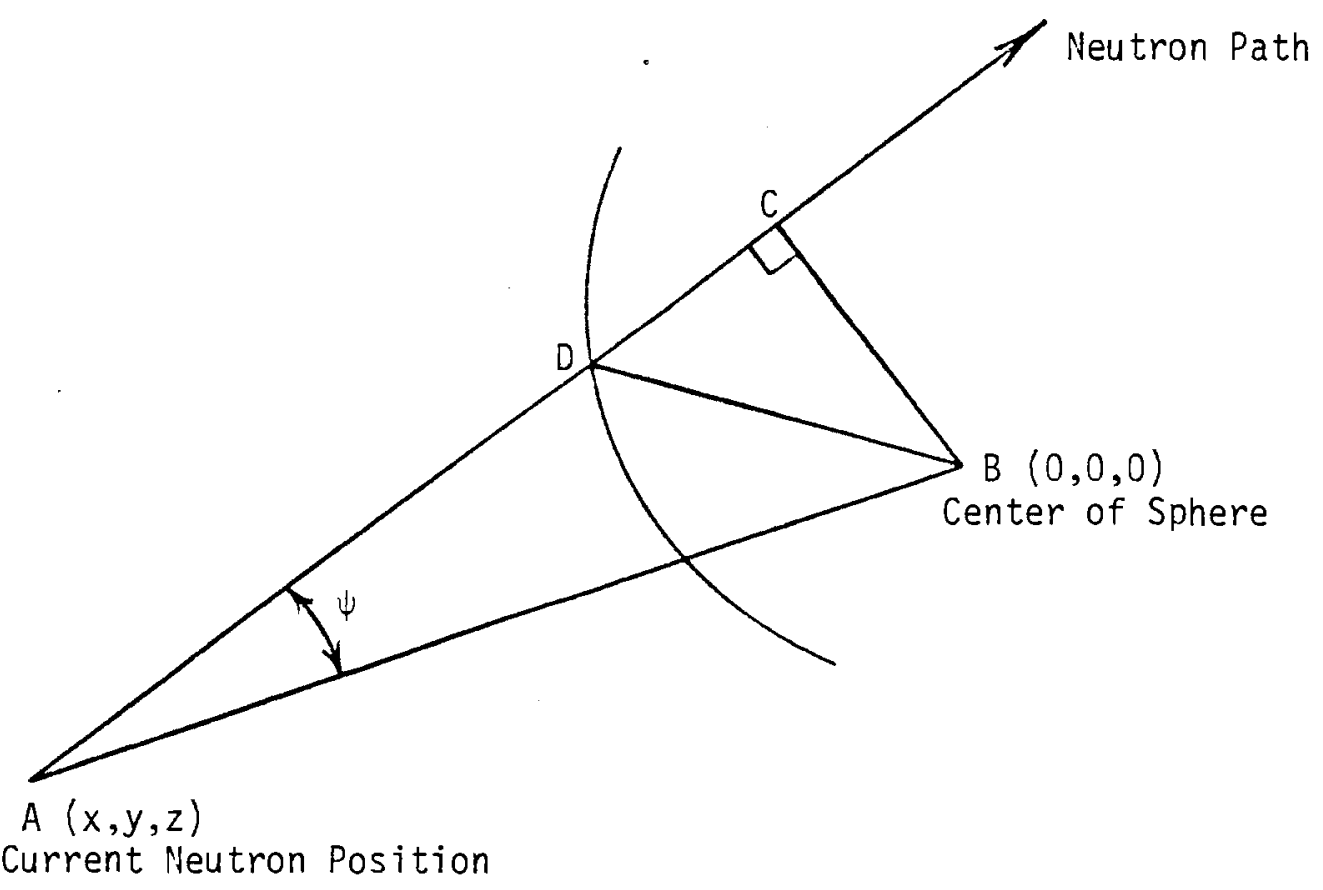

FIGURE III. Neutron Intersection with Sphere 
TABLE I. Comparison Between MCDAN and Data Given by Knight ${ }^{l}$

\begin{tabular}{|c|c|c|c|c|c|c|}
\hline$R / \lambda$ & & 0.1 & & 0.3 & & 0.5 \\
\hline$\underline{D / R}$ & KNIGHT & MCDAN* & KNIGHT & MCDAN* & KNIGHT & MCDAN* \\
\hline 2.0 & .07296 & $.06683 \pm .00155$ & .06813 & $.06370 \pm .00158$ & .06383 & $.06082 \pm .00161$ \\
\hline 3.0 & .02550 & $.02464 \pm .00112$ & .01898 & $.01895 \pm .00087$ & .01417 & $.01460 \pm .00068$ \\
\hline 4.0 & .01254 & $.01220 \pm .00022$ & .00757 & $.00765 \pm .00013$ & .00459 & $.00480 \pm .00009$ \\
\hline 5.0 & .00715 & $.00733 \pm .00041$ & .00352 & $.00373 \pm .00027$ & .00174 & $.00190 \pm .00011$ \\
\hline 6.0 & .00446 & $.00445 \pm .00059$ & .00179 & $.00186 \pm .00024$ & .00072 & $.00078 \pm .00010$ \\
\hline 7.0 & .00295 & $.00306 \pm .00044$ & .00097 & $.00104 \pm .00016$ & .00032 & $.00036 \pm .00005$ \\
\hline 8.0 & .00204 & $.00232 \pm .00022$ & .00055 & $.00064 \pm .00007$ & .00015 & $.00018 \pm .00002$ \\
\hline 9.0 & .00145 & $.00154 \pm .00011$ & .00033 & $.00035 \pm .00003$ & .00007 & $.00008 \pm .00001$ \\
\hline & $=$ & here radius & & & & \\
\hline & $D$ & inter-to-center s & ration & & & \\
\hline & $\lambda=$ & erator mean fre & & & & \\
\hline
\end{tabular}

*MCDAN modified to consider a system of two spheres 
TABLE II. MCDAN Calculated Dancoff Correction

Factors for Spheres, $\Sigma_{\mathrm{m}}=1.0 \mathrm{~cm}^{-1}$

\begin{tabular}{|c|c|c|c|c|c|c|}
\hline \multirow[b]{2}{*}{$\begin{array}{l}\text { Sphere } \\
\text { Volume } \\
\text { Fraction } \\
\end{array}$} & \multicolumn{2}{|c|}{$\mathrm{R}=0.005 \mathrm{~cm}$} & \multicolumn{2}{|c|}{$\mathrm{R}=0.02 \mathrm{~cm}$} & \multicolumn{2}{|c|}{$\mathrm{R}=0.7 \mathrm{~cm}$} \\
\hline & $\begin{array}{c}\text { Lattice } \\
\text { Pitch }(\mathrm{cm}) \\
\end{array}$ & $\begin{array}{c}\text { Dancoff } \\
\text { Correction } \\
\text { Factor } \\
\end{array}$ & $\begin{array}{l}\text { Lattice } \\
\text { Pitch }(\mathrm{cm}) \\
\end{array}$ & $\begin{array}{c}\text { Dancoff } \\
\text { Correction } \\
\text { Factor } \\
\end{array}$ & $\begin{array}{l}\text { Lattice } \\
\text { Pitch }(\mathrm{cm}) \\
\end{array}$ & $\begin{array}{c}\text { Dancoff } \\
\text { Correction } \\
\text { Factor } \\
\end{array}$ \\
\hline 0.005 & 0.0471 & 0.4292 & 0.1885 & 0.1414 & 0.9427 & 0.0218 \\
\hline 0.010 & 0.0374 & 0.6160 & 0.1496 & 0.2621 & 0.7482 & 0.0505 \\
\hline 0.025 & 0.0276 & 0.8132 & 0.1103 & 0.4989 & 0.5513 & 0.1312 \\
\hline 0.050 & 0.0219 & 0.8995 & 0.0875 & 0.6781 & 0.4376 & 0.2564 \\
\hline 0.100 & 0.0174 & 0.9492 & 0.0695 & 0.8196 & 0.3473 & 0.4469 \\
\hline 0.200 & 0.0138 & 0.9771 & 0.0551 & 0.9136 & 0.2756 & 0.6638 \\
\hline 0.300 & 0.0120 & 0.9866 & 0.0482 & 0.9474 & 0.2408 & 0.7766 \\
\hline 0.400 & 0.0109 & 0.9913 & 0.0438 & 0.9662 & 0.2188 & 0.8502 \\
\hline 0.500 & 0.0102 & 0.9941 & 0.0406 & 0.9770 & 0.2031 & 0.8942 \\
\hline
\end{tabular}


TABLE III. MCDAN Calculated Dancoff Correction

Factor for Spheres, $\Sigma_{\mathrm{m}}=2.0 \mathrm{~cm}^{-1}$

\begin{tabular}{|c|c|c|c|c|c|c|}
\hline \multirow[b]{2}{*}{$\begin{array}{c}\text { Sphere } \\
\text { Volume } \\
\text { Fraction }\end{array}$} & \multicolumn{2}{|c|}{$R=0.005 \mathrm{~cm}$} & \multicolumn{2}{|c|}{$R=0.02 \mathrm{~cm}$} & \multicolumn{2}{|c|}{$R=0.1 \mathrm{~cm}$} \\
\hline & $\begin{array}{c}\text { Lattice } \\
\text { Pitch }(\mathrm{cm})\end{array}$ & $\begin{array}{l}\text { Dancoff } \\
\text { Correction } \\
\text { Factor } \\
\end{array}$ & $\begin{array}{c}\text { Lattice } \\
\text { Pitch }(\mathrm{cm})\end{array}$ & $\begin{array}{c}\text { Dancoff } \\
\text { Correction } \\
\text { Factor } \\
\end{array}$ & $\begin{array}{c}\text { Lattice } \\
\text { Pitch }(\mathrm{cm}) \\
\end{array}$ & $\begin{array}{c}\text { Dancoff } \\
\text { Correction } \\
\text { Factor } \\
\end{array}$ \\
\hline 0.005 & 0.0471 & 0.2573 & 0.1885 & 0.0683 & 0.9427 & 0.0064 \\
\hline 0.010 & 0.0374 & 0.4365 & 0.1496 & 0.1416 & 0.7482 & 0.0170 \\
\hline 0.025 & 0.0276 & 0.6774 & 0.1103 & 0.3098 & 0.5513 & 0.0544 \\
\hline 0.050 & 0.0219 & 0.8145 & 0.0875 & 0.4975 & 0.4376 & 0.1313 \\
\hline 0.100 & 0.0174 & 0.9021 & 0.0695 & 0.6863 & 0.3473 & 0.2619 \\
\hline 0.200 & 0.0138 & 0.9550 & 0.0551 & 0.8382 & 0.2756 & 0.4771 \\
\hline 0.300 & 0.0120 & 0.9732 & 0.0482 & 0.8996 & 0.2408 & 0.6265 \\
\hline 0.400 & 0.0109 & 0.9828 & 0.0438 & 0.9331 & 0.2188 & 0.7339 \\
\hline 0.500 & 0.0102 & 0.9883 & 0.0406 & 0.9547 & 0.2031 & 0.8066 \\
\hline
\end{tabular}


TABLE IV. MCDAN Calculated Dancoff Correction

Factors for Spheres, $\Sigma_{\mathrm{m}}=3.0 \mathrm{~cm}^{-1}$

\begin{tabular}{|c|c|c|c|c|c|c|}
\hline \multirow[b]{2}{*}{$\begin{array}{r}\text { Sphere } \\
\text { Volume } \\
\text { Fraction } \\
\end{array}$} & \multicolumn{2}{|c|}{$R=0.005 \mathrm{~cm}$} & \multicolumn{2}{|c|}{$R=0.02 \mathrm{~cm}$} & \multicolumn{2}{|c|}{$\mathrm{R}=0.1 \mathrm{~cm}$} \\
\hline & $\begin{array}{c}\text { Lattice } \\
\text { pitch }(\mathrm{cm}) \\
\end{array}$ & $\begin{array}{l}\text { Dancoff } \\
\text { Correction } \\
\text { Factor } \\
\end{array}$ & $\begin{array}{l}\text { Lattice } \\
\text { Pitch }(\mathrm{cm}) \\
\end{array}$ & $\begin{array}{l}\text { Dancoff } \\
\text { Correction } \\
\text { Factor } \\
\end{array}$ & $\begin{array}{c}\text { Lattice } \\
\text { Pitch }(\mathrm{cm}) \\
\end{array}$ & $\begin{array}{l}\text { Dancoff } \\
\text { Correction } \\
\text { Factor } \\
\end{array}$ \\
\hline 0.005 & 0.0471 & 0.1858 & 0.1385 & 0.0467 & 0.9427 & 0.0023 \\
\hline 0.010 & 0.0374 & 0.3290 & 0.1496 & 0.0887 & 0.7482 & 0.0076 \\
\hline 0.025 & 0.0276 & 0.5759 & 0.1103 & 0.2212 & 0.5513 & 0.0293 \\
\hline 0.050 & 0.0219 & 0.7428 & 0.0875 & 0.3868 & 0.4376 & 0.0727 \\
\hline 0.100 & 0.0174 & 0.8606 & 0.0695 & 0.5860 & 0.3473 & 0.1753 \\
\hline 0.200 & 0.0138 & 0.9338 & 0.0551 & 0.7726 & 0.2756 & 0.3645 \\
\hline 0.300 & 0.0120 & 0.9603 & 0.0482 & 0.8554 & 0.2408 & 0.5190 \\
\hline 0.400 & 0.0109 & 0.9744 & 0.0438 & 0.9047 & 0.2188 & 0.6433 \\
\hline 0.500 & 0.0102 & 0.9828 & 0.0406 & 0.9331 & 0.2031 & 0.7323 \\
\hline
\end{tabular}




\section{REFERENCES}

1. "SUPERDAN: Computer Programs for Calculating the Dancoff Factor of Spheres, Cylinders and Slabs," J. R. Knight, ORNL/NUREG/CSD/TM-2, March 1979. 
APPENDIX A

Input to MCDAN

Input to MCDAN is straighforward and can be easily modified by the user to suit his own needs. The version of the code as listed in Appendix B requires the following input.

\begin{tabular}{|c|c|c|c|}
\hline CARD \# & FORMAT & VARIABLE & DESCRIPTION \\
\hline 1 & A1 & ISC & $\begin{array}{l}\text { ISC }=S \text { to calculate the Dancoff correction } \\
\text { for an array of spheres. ISC }=R \text { to calculate } \\
\text { the Dancoff Correction for an array of rods. }\end{array}$ \\
\hline 2 & $\begin{array}{l}\text { List } \\
\text { Directed }\end{array}$ & $\begin{array}{l}\mathrm{R}, \mathrm{SIG}, \\
\mathrm{VF}\end{array}$ & $\begin{array}{l}R=\text { sphere or rod radius in centimeters } \\
\text { SIG - moderator macroscopic total cross } \\
\text { section, } \mathrm{cm}^{-1} \\
V F \text { - } \\
\text { sphere volume fraction or rod lattice } \\
\text { pitch. }\end{array}$ \\
\hline
\end{tabular}

Control returns to Card 2. To terminate execution input R, SIG and VF as 0.0. 
APPENDIX B

Listing of MCDAN 


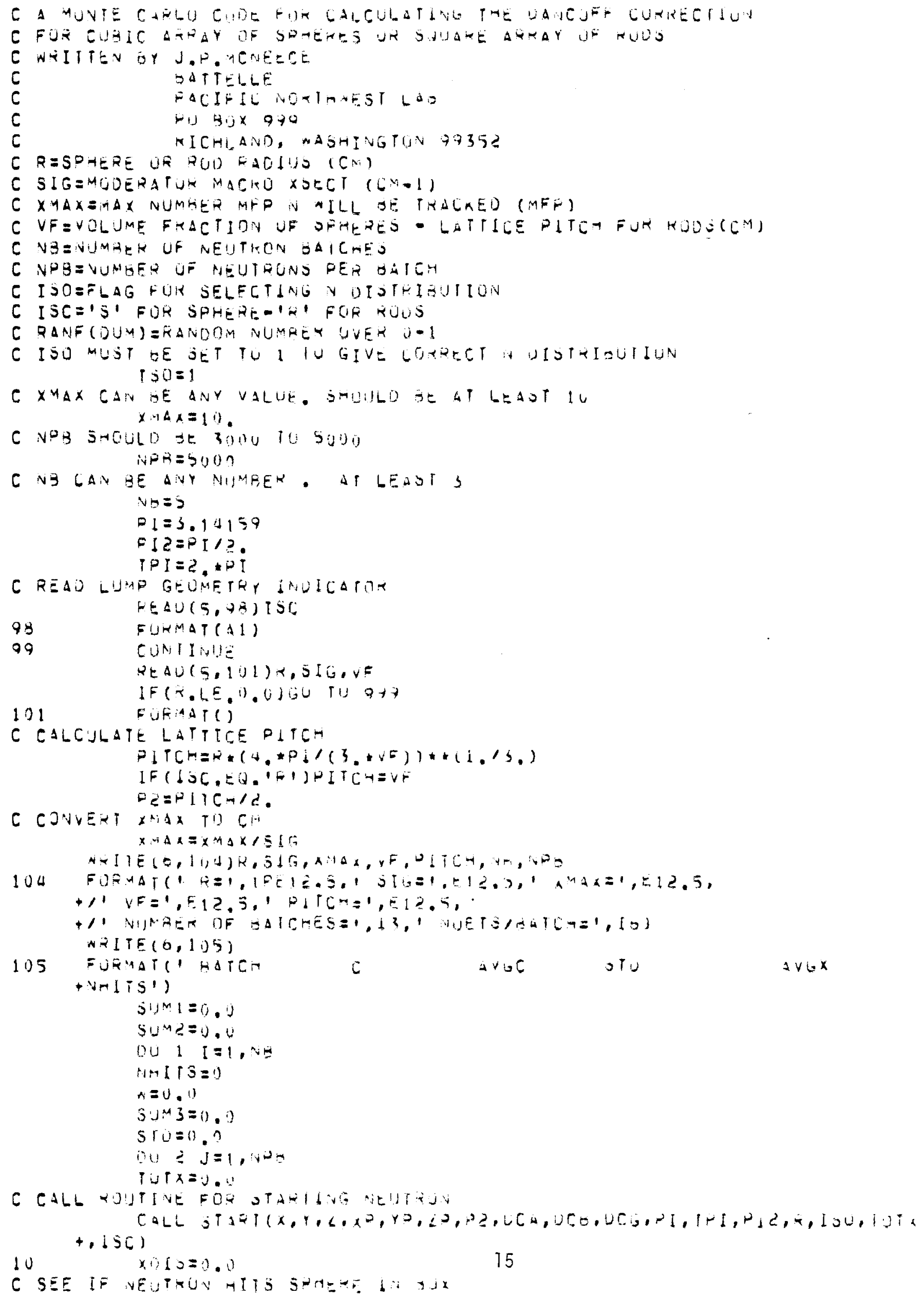




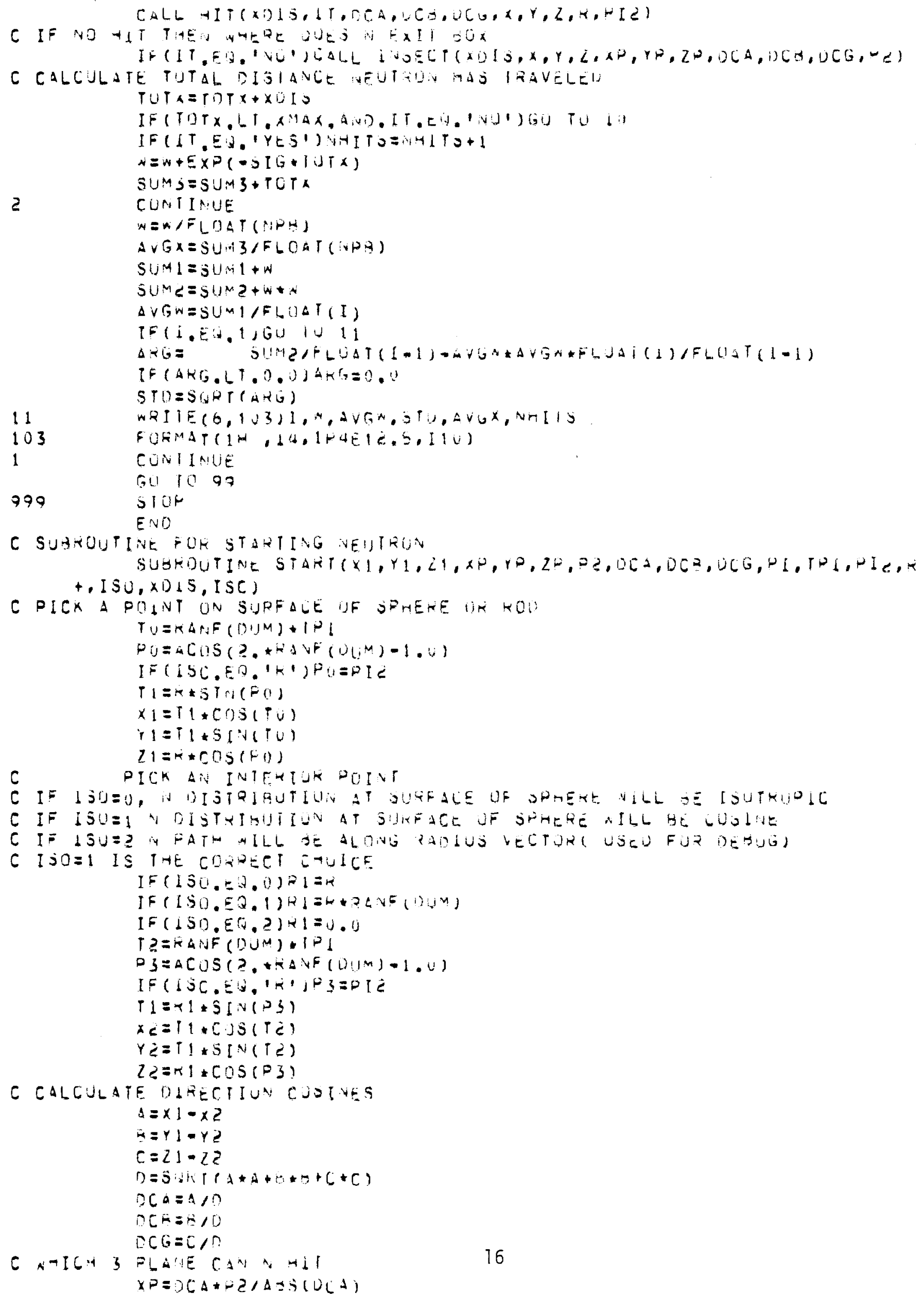




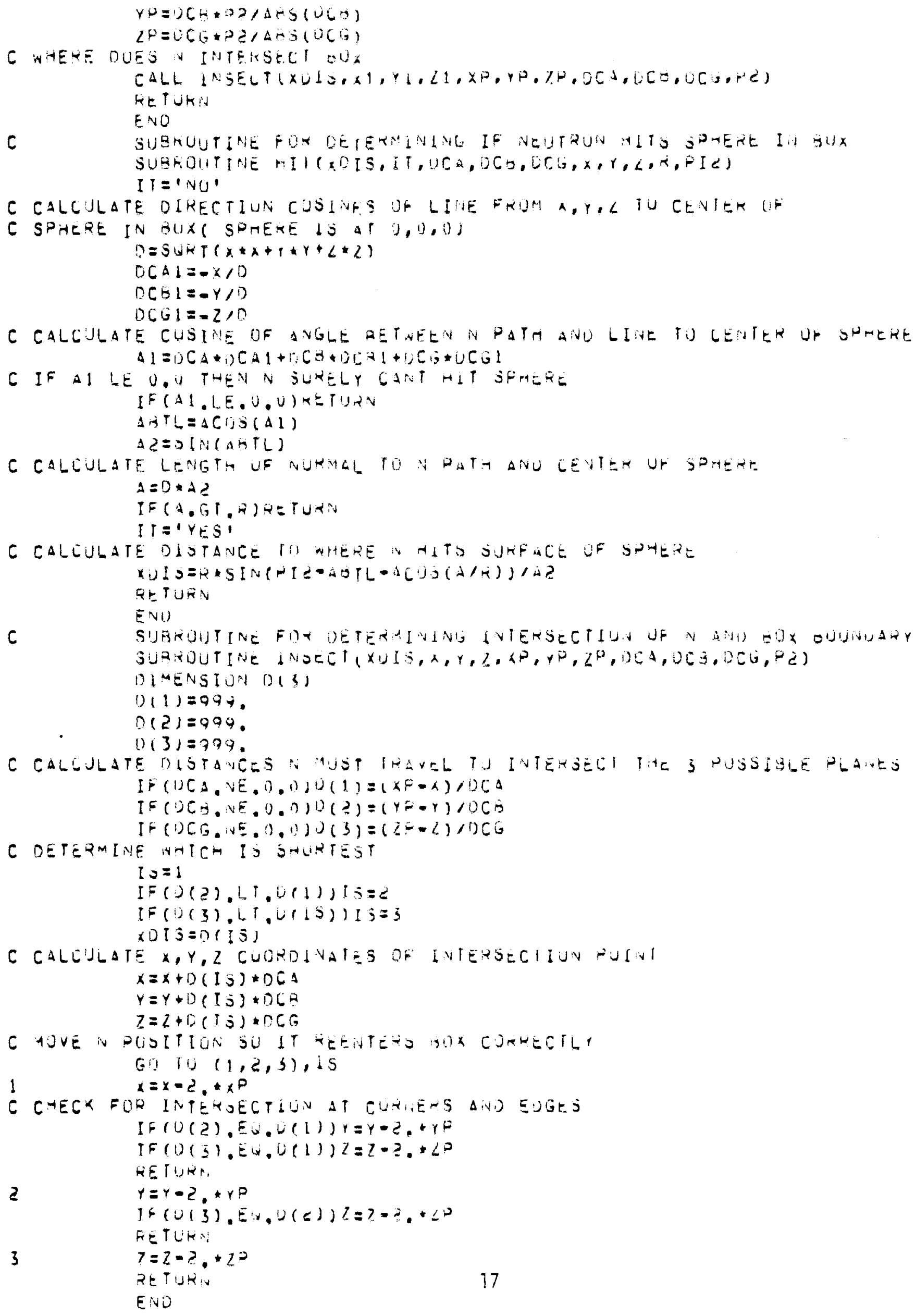


DISTRIBUTION

No. of

Copies

OFFSITE

A. A. Churm

DOE Patent Division

9800 South Cass Avenue

Argonne, IL 60439

27 DOE Technical Information Center

ONSITE

1 DOE Richland Operations Office

H. E. Ransom

3 Rockwel1 Hanford Operations

RD Carter

Tang Chiao

WE Matheison

21 Pacific Northwest Laboratory

WE Bickford

SR Bierman

$\mathrm{CL}$ Brown

WE Converse

DA Dingee

BM Durst

BF Gore

UP Jenquin

DA Kottwitz

BR Leonard

RA Libby

RC Lloyd

GW McNair

JP McNeece

WL Purcel1

JK Thompson

TJ Trapp

Technical Information Files (3)

Publishing Coordination 
